\title{
Sex in an Evolutionary Perspective: Just Another Reaction Norm
}

\author{
Malin Ah-King $\cdot$ Sören Nylin
}

Received: 16 June 2010/Accepted: 22 October 2010/Published online: 13 November 2010

(C) The Author(s) 2010. This article is published with open access at Springerlink.com

\begin{abstract}
It is common to refer to all sorts of clear-cut differences between the sexes as something that is biologically almost inevitable. Although this does not reflect the status of evolutionary theory on sex determination and sexual dimorphism, it is probably a common view among evolutionary biologists as well, because of the impact of sexual selection theory. To get away from thinking about biological sex and traits associated with a particular sex as something static, it should be recognized that in an evolutionary perspective sex can be viewed as a reaction norm, with sex attributes being phenotypically plastic. Sex determination itself is fundamentally plastic, even when it is termed "genetic". The phenotypic expression of traits that are statistically associated with a particular sex always has a plastic component. This plasticity allows for much more variation in the expression of traits according to sex and more overlap between the sexes than is typically acknowledged. Here we review the variation and frequency of evolutionary changes in sex, sex determination and sex roles and conclude that sex in an evolutionary time-frame is extremely variable. We draw on recent findings in sex determination mechanisms, empirical findings of morphology and behaviour as well as genetic and developmental models to explore the concept of sex as a reaction
\end{abstract}

M. Ah-King $(\square)$

Department of Ecology and Evolutionary Biology, University of California Los Angeles, 621 Charles E. Young Drive South, Box 951606, Los Angeles, CA 90095, USA

e-mail: mahking@ucla.edu

M. Ah-King

Centre for Gender Research, Uppsala University, Box 634,

75126 Uppsala, Sweden

S. Nylin

Department of Zoology, Stockholm University,

10691 Stockholm, Sweden norm. From this point of view, sexual differences are not expected to generally fall into neat, discrete, pre-determined classes. It is important to acknowledge this variability in order to increase objectivity in evolutionary research.

Keywords Phenotypic plasticity - Sexual selection . Sex determination - Sex change - Sex role reversal . Gender bias

Descriptions in evolutionary biology of males in general as active and females as passive are historical biases that can be traced back to Darwin's account of sexual selection theory and the society he was part of (Hrdy 1986). Even if evolutionary theory has repeatedly replaced stereotypic notions of females and males by more variable ones (Gowaty 2003), gender bias ${ }^{1}$ still influence research in animal behaviour (Hrdy 1986; Fausto-Sterling et al. 1997; Gowaty 1997; Lawton et al. 1997; Zuk 2002; Roughgarden 2004).

For example, Lawton et al. (1997) show that gender biases affect interpretation of animal behaviour in studies at the molecular, individual and population level. In a study on Pinjon Jays, the researchers looked for aggressive dominant behaviour in peaceful males and at the same time female aggressiveness was discarded as a bird version of PMS (Pre Menstruation Syndrome), the Pre Breeding Syndrome. Lawton et al.'s reinterpretation of the data gives

\footnotetext{
${ }^{1}$ Here we use the term gender as socially constructed behaviours and attributes that a given society considers appropriate for women and men. Thus, by gender bias we mean that certain characteristics have been expected from females and males, blinding researchers to patterns in nature. By gender-neutral we mean that no special characteristics are attributed to females and males as initial assumptions, it does not mean that there are no sex differences.
} 
a more comprehensive picture: it turns out that in this species only the females are fighting for breeding territories. Hence, stereotypic notions of females and males may be a hindrance in evolutionary research. We believe it would be beneficial to researchers to move away from thinking about biological sex as something static and deterministic; instead it should be recognized that evolutionary theory on sex determination and sexual dimorphism rather suggests that sex should be viewed as any other plastic trait-as a reaction norm.

When describing phenotypically plastic traits, a reaction norm is the range of phenotypic expressions that one genotype can give rise to, in response to different environmental conditions (e.g. Gotthard and Nylin 1995; Stearns and Hoekstra 2005). Lately, the study of phenotypic plasticity have come to include aspects of development (changes during ontogeny), allometry (how changes in different aspects of the phenotype are correlated) and plasticity (environmental effects leads to different phenotypes from one genotype) (Schlichting and Pigliucci 1998). To produce complex phenotypes and in order to respond to internal or external influences, the development requires flexible systems of regulatory control. The mechanisms by which phenotypic plasticity is produced are switches that are sensitive to both/either genetic and environmental input on an already existing phenotype (West-Eberhard 2003). These switches, that may be temporarily active, enables adjustment to stimuli as well as buffering against internal and external stimuli. West-Eberhard emphasizes that the start-out-phenotype is always a product of inherited influences of genes and environment intertwined that is responsive to genetic and environmental inputs. Thus, a phenotype does not originate from genes, but from a reactive phenotype.

Sex in animal biology is defined by the production of gametes; an individual producing eggs is a female and a male produces sperm. When it comes to sex itself, the reaction norm concept is most clearly applicable to cases of sex change and to environmental sex determination. For example, in crocodiles, the same genotype can give rise to a female or a male depending on the temperature during incubation (Pieau et al. 1999; see Fig. 1), thus the traits of both sexes are part of the reaction norm for that genotype. However, we will propose here that the reaction norm concept can and should be extended to taxa with genetic sex determination and to traits that differ between the sexes. It is important to note that evidence of constraints does not refute the notion of sex as a reaction norm. For example, in a species with chromosomal sex determination, the reaction norm of sex determination may be non-plastic (low responsiveness to environmental influences) and irreversible, or plastic as in species with a sex determination system combining both chromosomal and environmental

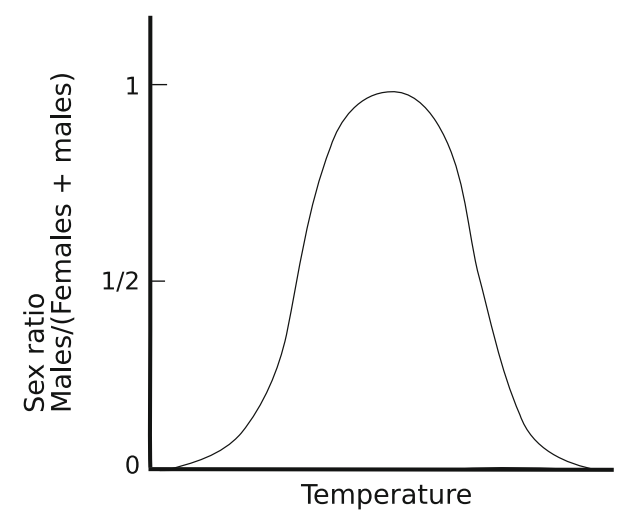

Fig. 1 Response in sex ratio to incubation temperature in crocodiles. Females are produced at low and high temperatures while intermediate temperatures result in male offspring

factors. Furthermore, the sex differences (in traits other than gamete size) that may arise once sex has been determined will always have a plastic component, to which the reaction norm concept is applicable.

Reaction norms have five attributes: they can be reversible or irreversible (e.g. sex change), they differ in the amount of plasticity-large or small response to environmental change (e.g. environmental or genetic sex determination), they differ in the rapidity of the response and in competence, that is "the ability of the developmental system to respond to environmental stimuli only during particular time "windows" in the ontogenetic trajectory" (Schlichting and Pigliucci 1998). One example of irreversible developmental plasticity is the induction of different adult morphs in insects that have experienced different larval environments. Reversible plasticity includes phenotypically flexible traits such as levels of subcutaneous fat stored by a vertebrate (e.g. human obesity). "Behaviour" is just another word for very flexible and thus plastic traits. The resulting phenotype is in all of these cases determined by effects of both genes and environment on the phenotype, in two ways. First, even when the trait is entirely plastic (i.e. there is no genetic variation present for the trait, all individuals have the same reaction norm) genes are of course needed to produce the phenotype induced by a particular environment. Second, even for traits that are clearly very plastic (such as human obesity) typically there is actually also clear genetic variation present (reaction norms differing between genotypes, resulting in interactions between the effects of genes and environment in the sense of quantitative genetics).

The usual use of the term reaction norm is to describe the proximate causation of a range of phenotypes due to one genotype producing different phenotypes in different environments, however for the purposes of the present paper it is also of importance that reaction norms may vary between genotypes and hence be the target of selection. 
We mean that there is not only flexibility in the proximate causation of sexes but also in ultimate causation of sexes, as selection pressures change over evolutionary time. Thus, sex, just like any other character can evolve and be selected upon. Behaviour and morphology are both functions of the evolutionary influence of ecological variables on organisms. In this context, we can view sex from morphology to behaviour as a continuum, with effects of genes and environment on the phenotype resulting in sex determination, sex change, genitals, sexual characters, sexual behaviours and mate choice/competition. Also, the causal direction is not straight-forward, changes in behaviour may change gene frequencies, morphology as well as the environment.

As mentioned above, even in genetically sex-determined species, sex can be viewed as a reaction norm. In fact, the distinction between genetic and plastic sex determination is something of a false dichotomy. Recent findings in sex determination suggest that environmental and genetic sex determination share the same proximate mechanism, a sexdetermination substance increases either due to environmental influences like temperature, or due to genes on sex chromosomes and reaching a threshold level at a critical time results in the development of female/male gonads. Kraak and DeLooze (1993) suggest that the growth rate or gonad size at a certain time is the fundamental determinant of sex in vertebrates, in both environmentally and genetic sex determination systems.

Similarly, recent plasticity theory suggests that there is no strict borderline between plastic and genetic determination of the phenotype in general. Environmental and genetic cues are often combined in ontogeny, to ensure that the developmental pathway that best fits the current environment is followed (Leimar et al. 2006).

...sexuality in the damselfish shows a high potential for adaptation to extrinsic factors, enabling the fish to exploit sex as a phenotypic character. (Fishelson 1998)

The concept of sex being a reaction norm is not new; for example, researchers working in fields such as sex-determining mechanisms or with sex-changing species might find it obvious. However, this perspective has not received enough attention, especially in the behavioural sciences (including evolutionary psychology) and in popular accounts of science with an impact on how sex is viewed by society. In addition, recent findings on the molecular genetics of sex determination and sex-limited gene expression illustrate that the reaction norm perspective is ultimately more correct than the view of sex differences as something genetically predetermined. For instance, when Kimchi et al. (2007) recently found that a key sex attribute in mice - mating behaviourcan be completely and rapidly switched from female to male behaviour by surgically or genetically manipulating pheromone perception, this may have been a startling finding to some. However, it is quite in line with the reaction norm perspective on sex. The researchers indeed suggest that the neural pathways for both female and male mating behaviour are present in both sexes, and that it is the sex-specific pheromone reception that determines which behaviour is activated (Kimchi et al. 2007).

From a reaction norm perspective on sex, sex differences are not expected to always or even typically fall into discrete classes (even when leaving aside the obvious case of hermaphroditic organisms, for instance most plants). We may recognise the sexes as categories, on the basis of morphology or-when applicable—sex chromosomes, and it is of course often useful to search for and investigate statistical differences in other traits between groups of individuals of different sex, as has successfully been done in countless sexual selection studies (Andersson 1994). However, it must always be recognized that an individual need not be distinctly placed in its sex based on a single character, as shown by plumage patterns in hummingbirds, where both females and males can have "male-like" or "female-like" plumages (Bleiweiss 2001). It is not even always possible to place an individual in either of the sexes, as exemplified by intersexuals (Fausto-Sterling 1993, 2000a, b; Pieau et al. 1999).

In an evolutionary sense, we can observe that sex determination, sex change, sex differences in appearance and behaviour are immensely variable among organisms (see Figs. 2, 4), and these characters have been under the influence of environmental selection pressures (Kvarnemo and Ahnesjö 1996; Fishelson 1998; Shine 1999; WestEberhard 2003; Munday et al. 2006a). Below, we will show how it is likely that evolutionary flexibility (variable sex determination among species), environmental sex determination, ontogenetic shifts in sex, and hermaphroditism are all phenomena that can be linked to and illustrate the basic plasticity and flexibility of sex, sex attributes and behaviour. This review deals specifically with variation in sex, morphology and behaviour, obviously there are lineages with conserved sex determination mechanisms (such as mammals and birds) and species with distinct female and male phenotypes at least for some traits (such as strongly sexually selected ones); thus there is a continuum between flexibility and constraints/maintenance of traits. We show that even in species with genetic sex determination and pronounced sex differences, the reaction norm perspective on sex provides a tool to interpret variation within and between sexes. It is a paradox that all biologists are aware of variation in sex determination, sex change and alternative reproductive strategies, and still we continue to present this variation in terms of a two-sex norm and the deviations from this norm as alternatives and sex role-reversals. 


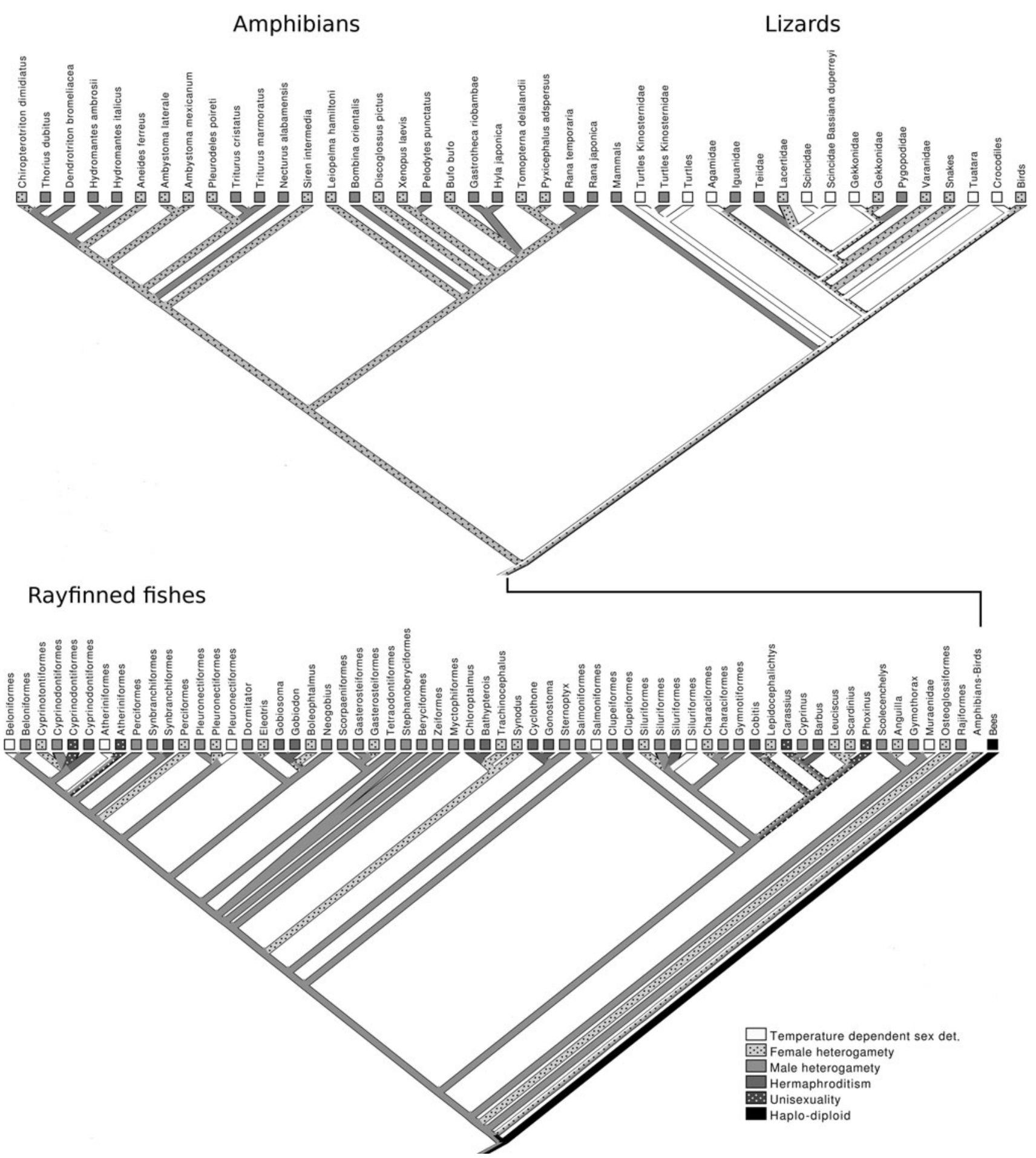

Fig. 2 Phylogeny of changes in sex determination mode. Sex determination is immensly variable, this phylogeny is an attempt to illustrate this diversity. Taxa has been chosen to illustrate transitions between sex determination systems. We used phylogenies on amphibians from Hillis and Green (1990), on lizards and snakes from de Queiros and Martin

We argue against the norm of dichotomous sexes, and point out that from our perspective-sex as a reaction norm-variation is explicitly included instead of looked (1996a, b), on fishes from Mank et al. (2006) the overall topology is derived from the Tree of life project (Maddison and Schulz 1996-2006). Data on reptiles was compiled from Bull (1980), on amphibians from Hillis and Green (1990), on Bassiana duperreyi from Shine et al. (2002), on birds from Ellegren (2000), on fishes from Mank et al. (2006)

upon as deviation. Both discrete and continuous sexual phenotypes are functions of developments regulated by switches that are variable and poly-genetic (West-Eberhard 
2003). Thus even in species with typically large sex differences and genetic sex determination, an individual's phenotype is dependent upon environmental influences in the development.

We summarise the basic knowledge regarding sex determination and the development of sexual differences as well as point out new findings that support the concept of viewing sex as a reaction norm. In the final part, we focus on the consequences of this view and the benefits that we believe it brings.

\section{Plasticity in Sexual Development}

The reason for variation in sex is that sex and characters that are statistically associated with one sex develop in several steps:

1. One or several genes ("sex-determining genes") initially start the cascade of gene expression and hormonal activity leading to the formation of an individual of a particular sex. The expression of such genes is more or less dependent on environmental cues (including the influence of the expression of other genes) in different organisms. These genes may also be more or less active in themselves, in a particular individual, i.e. they can be genetically variable.

2. The hormones that are released as a result of the expression of these sex-coding genes can be more or less dependent on environmental cues and genetically variable.

3. The response to these hormones can also be plastic and genetically variable, and furthermore such responses are only the start of complex ontogenetic cascades of phenotypic development, with much scope for introducing variation at subsequent levels.

4. Among humans and some other animals with culture, the culture further affects behaviour and morphology, in another level of plasticity. If men are more expected to choose physically demanding jobs or work out by lifting weights than women, this will for instance obviously increase any physical differences already present between the sexes. Culture may even affect the genes (Richerson and Boyd 2005; Laland and Janik 2006). For example, in human cultures where keeping cows and consumption of fresh milk has been tradition for a long time, most adults can digest lactose. This is not the case in other cultures, which suggests that the cultural habit of ingesting dairy has selected for an increase in the frequency and/or expression of the gene that enables adults to digest lactose (Richerson and Boyd 2005). In an analogous manner, cultural differences between the sexes may also have lead to different selection pressures.
In addition, it is often assumed that hormones unidirectionally regulate phenotype expression, but lately there is evidence for a feedback between phenotype and circulating hormones. In barn swallows, androgen levels are correlated with the sexually selected plumage pattern. Darker males have a higher reproductive success and more circulating androgens than paler ones. Manipulating male plumage colouration actually alters the level of circulating androgen (Rubenstein and Hauber 2008).

Thus, the expression of sex and sex-related characters are always more or less under the influence of both environmental and genetic variation. The same reasoning about the variability of sex and sex attributes due both to genes and the environment has also been put forward by Roughgarden (2004), although not presented in terms of a reaction norm. In contrast to Roughgarden, we do not claim that this is a reason to reject sexual selection theory, see Prospects below.

\section{A Model of Sex in an Evolutionary Perspective}

Considering sex as a reaction norm provides a genderneutral way of modelling biological sex and sex-linked traits, in the sense that such sex attributes are not seen as pre-determined aspects of the sexes but as the outcome of genetic and environmental influences during ontogenetic development. This view of sexual differences is supported by inferences from genetic models. There are several ways to model phenotypic plasticity, by means of quantitative genetics, optimality models and complexity theory (see Schlichting and Pigliucci 1998), here we exemplify with one quantitative genetic model. It is worth noting that Via and Lande's (1985) genetic model of phenotypic plasticity is identical in essence to Lande's model of sexual dimorphism (Lande 1987). That is, in much the same way as phenotypic plasticity (or, rather, genetic constraints on plasticity) can be modelled as a (greater or lesser) genetic correlation between different environments, sexual dimorphism can be seen as the result of a partially broken genetic correlation between the sexes. In the model of phenotypic plasticity, a genotype expressed in two environments is modelled as two genetically correlated characters. If the genotype produces the same phenotype in both environments, the genetic correlation is high and there is no phenotypic plasticity. Conversely, different phenotypes seen in different environments imply a less strong genetic correlation between environments and thus the presence of plasticity. Likewise, in the model of sexual dimorphism, strong sexual dimorphism is only possible if there is a low genetic correlation between the sexes (Lande 1987). This could be due to genes carried on the sex chromosomes or sex differences in the number of alleles of additive genes. 
However, since most genes are found in both sexes, a poor correlation is presumably often an evolved condition where one or more genes have taken the role of modifying the expression of other genes according to sex.

This close parallel between the models illustrates how an individual's sex (i.e. the egg or sperm production and the associated hormonal activity) can be viewed as the "inner environment" that causes different gene expression in the sexes, a form of phenotypic plasticity, which is confirmed by recent findings that thousands of genes found in both sexes are expressed differently in females and males (Drosophila: Parisi et al. 2004; mice: Yang et al. 2006). It is ultimately for this reason that even very small genetic differences ("sex-determining genes") can produce strong sexual dimorphism, but the potential is also clearly present for traits (or whole suites of developmentally connected traits) to be expressed in a given individual in a way which is not "typical" for its sex. This ever-present role of plasticity in development helps explain the evolutionary flexibility of traits associated with sex.

Another, maybe more accurate way of modelling reaction norms is through considering the reaction norm itself as a trait, in contrast to viewing the expression of a trait in different environments as a genetic correlation (Schlichting and Pigliucci 1998). When investigating the evolution of plasticity one would expect the genes determining a reaction norm, for example those genes involved in processing environmental signals, to be selected upon (Schlichting and Pigliucci 1998). When considering sex as a reaction norm, this might be a fruitful way to move forward, and here as in other reaction norms, change can come about due to alterations in any part of the information pathway.

In humans, for example, genes on the sex chromosomes decide the inner environment that makes sexual characteristics develop, by the action of genes that actually exist in both sexes. Human intersexuality, as well as sex change by transsexuals-intake of hormones induce secondary sexual characters-illustrates the plasticity of such traits (Fausto-Sterling 1993, 2000a, b). Among humans there are different levels of hormones resulting in a spectrum of phenotypes (from sex determination to morphology of sexual characteristics). In many other species, sex determination itself is entirely plastic, and in yet others individuals can even change sex.

\section{Sex Change}

Sex change - the extreme example of sex plasticity-is shown in a large range of animal taxa, such as annelids, shrimps, snails and fishes (Policansky 1982; Munday et al. 2006a). Sex change may be induced by social environment, at a fixed body size, or repetitively expressed in response to potential reproductive benefits (Munday et al. 2006a). In line with viewing sex as a reaction norm shaped by selection, the timing of sex change often appears to be an adaptive response to the individual's ecological and social environment (Munday et al. 2006a).

In organisms with indeterminate growth, both sexes generally increase their reproductive success with increasing size, but the shape and slope of the fitness functions may differ between males and females. In labrid fishes, sex change from female to male is commonly occurring. In a comparative study of sex change in species with male care of eggs contrasted with related species that do not care, both males and females of all the four species receive higher reproductive success with increasing body sizes (Warner and Lejeune 1985). However, in species which do not show paternal care, males have much greater reproductive success than females of the same large body size and these species also show the strongest expression of sex change (Warner and Lejeune 1985). Such patterns show that sex change itself is a variable trait which can be selected upon, and its expression is determined by the strength of these selection pressures.

We do not deal extensively with plants here, because of the less straight-forward concept of what constitutes an "individual" in plants and other taxa with "open germ lines" (Buss 1987). However, it could be noted that sex change occurs in a large number of plant species and has been shown to be induced by many environmental factors as well as by age and size (Freeman et al. 1980). Generally, harsh conditions, such as dry soil and high temperature, trigger a shift towards more male allocation. This makes sense in the common case where male reproduction is less costly than female reproduction. However, in contrast to animals, only a few of these plants change sex completely, most of them are showing a reversible reallocation of resources between female and male function. If sex change in plants is correlated with resource state, it would certainly be advantageous to be able to change back and forth between female and male allocation in correspondence to variable environmental conditions (Freeman et al. 1980).

Additional examples of sex change will be mentioned in the next section, since sex change in some taxa grades into environmental sex determination.

\section{Sex Determination Plasticity}

Here we give a short overview of the variation in animal sex determination systems, focusing mainly on vertebrates, and at the same time examine the role of plasticity in sex differentiation and the links between different evolutionary phenomena and sexual differentiation. Among vertebrates, the majority of species have two sexes, and the cell 
differentiation during development is conserved, but there is a diversity of factors that triggers the sex determining pathway (Graves and Pleichel 2010). Even the systems for genetic sex determination are evolutionary flexible, showing that "male" or "female" are not rigid categories deterministically decided by genes "for" a particular sex; in fact genetic and environmental sex determination systems repeatedly evolve from each other (see Fig. 2).

\section{Overview of Sex Determination Systems}

The sex of individuals is determined either by genetic sex determination, often with heteromorphic sex chromosomes, as in birds, mammals, and most lizards and snakes, or by environmental sex determination as in most turtles and all crocodiles. Shifts between these modes have occurred multiple times (Bull 1980). In some lineages, such as mammals and birds, the sex determination system is conserved, while in others, it has changed multiple times during evolution. In fish, chromosomes controlling sex determination differ even between closely related species and different sex determination systems may even coexist within the same species (Froschauer et al. 2006), demonstrating that these systems may be evolutionarily unstable. Different sex-determining mechanisms that could be seen as incompatible might occur concurrently also in other vertebrates, as in a lizard species in which genetic and temperature dependent sex determination occurs simultaneously in a single population (Shine et al. 2002). At cold temperatures the genetic sex determination is overridden by temperature, resulting in primarily male offspringincluding both $\mathrm{XY}$ males and $\mathrm{XX}$ males.

Comparative mapping of the $\mathrm{Z} / \mathrm{W}$ and $\mathrm{X} / \mathrm{Y}$ sets of sex chromosomes suggests that the sex-determining genes in mammals and birds, as well as in snakes, have developed from different autosomal chromosomes (Ellegren 2000; Matsubara et al. 2006). In addition, a recent theoretical model suggests that sexually antagonistic selection can give rise to a shift in sex determining chromosomes (van Doorn and Kirkpatrick 2007). The model shows that a new sex-determining gene on an autosomal chromosome can spread if linked with a gene that is under sexually antagonistic selection. Thus, evolution of the genome could be determined by behaviour as well as the other way around.

Some sex determination systems are more stable, as in mammals and birds. However, even within birds, the sex chromosomes show a large variation in size and degree of differentiation. In fact, most genes involved in vertebrate sex determination seem not to be conserved across taxa (Ellegren 2000), which exemplifies the variation and evolutionary flexibility of sex determination at the genomic level. This is not surprising from the reaction norm perspective, since "sex chromosomes" are nothing more (or less) than the chromosomes which presently happen to harbour the gene or genes responsible for initiating the sexual differentiation cascade, subsequently involving many other genes that are typically common to both sexes. A shift in the details of genetic sex determination simply implies that genes elsewhere in the genome have taken over this role.

Sex determination modes in teleost fish include male and female heterogamety, protandrous, protogynous and simultaneous hermaphrodites as well as unisexuality and environmental sex determination systems (Mank et al. 2006). Interestingly, most of these modes of sex determination also have multiple evolutionary origins and due to the large variability between modes it has not yet been possible to determine which one is ancestral (Mank et al. 2006).

\section{Environmental Sex Determination}

The effect of temperature on sex differs between species: low temperatures produce females in lizards but males in turtles (Bull 1980). According to one hypothesis, there are selective advantages to having temperature-dependent sex determination when male and female fitness benefit differently according to temperature (for alternative hypotheses see Shine 1999). An embryo that is able to respond to its immediate environment and become the sex that is most benefited will then have an advantage over those that are genetically sex-determined (Bull 1980).

The social environment is one of the factors that can regulate sex determination, as has been shown for example in the labrid fish Thalassoma bifasciatum (Munday et al. 2006b). An individual that is brought up on its own almost exclusively develops into a female, but in a group of three one develops into a male. In this species there is also a possibility to first reproduce as a female and then change sex into a male.

In clown fishes (Pomacentridae), there is great variation in sex determination: genetic sex determination, hermaphrodites that are protogynous, hermaphrodites that are protandrous, as well as bisexual species in which the pregonads include both testicles and ovaries. Some species use a specific permanent habitat while others occur in different habitats or change habitat with age. With few exceptions, species living in different habitats have genetic sex determination while species living in permanent habitats are hermaphrodites in which sex determination is socially controlled (Fishelson 1998). The more permanent the habitat and the isolation of the reproductive group, the more pronounced is the sex change. Hence, adaptation to environmental factors have influenced the sex determination mode in these fishes; they show a high plasticity in sexuality which has enabled them to use sex as a 
phenotypic character (Fishelson 1998). One example of a sedentary species is the group-living clownfish Amphiprion perideraion, in which all individuals are first males and then-depending on the social environment - may develop into females (Hattori 2000). The presence of a larger species of clown fish that lives in the same sea anemone also influences the reproductive status and sexual development of this species.

The bacterium Wolbachia can cause sex reversal in many terrestrial arthropods. This microbe can only be maternally inherited and has therefore evolved a mechanism to change genetical males into phenotypical females (Wilkinson 1998). Wolbachia has been found in a wide array of organisms, such as insects and other arthropods (Wilkinson 1998). In some populations of the butterfly Acraea encedon, Wolbachia-infection has resulted in extreme female bias in adult sex ratio, which in turn has led to female lekking swarms that are absent from less femalebiased populations (Jiggins et al. 2000).

\section{Gene Regulation}

Chromosomal sex determination is known to occur in two ways. Either, as in mammals, the expression of a gene on the Y-chromosome determines male differentiation. Alternatively, as for example in Drosophila, the balance between $\mathrm{X}$ chromosomes and autosomes determine female differentiation (see Fig. 3). In birds, the differentiation mode is not yet determined; it could be similar to either of the above modes (Ellegren 2000) or possibly a unique combination of both (Nakagawa 2004).

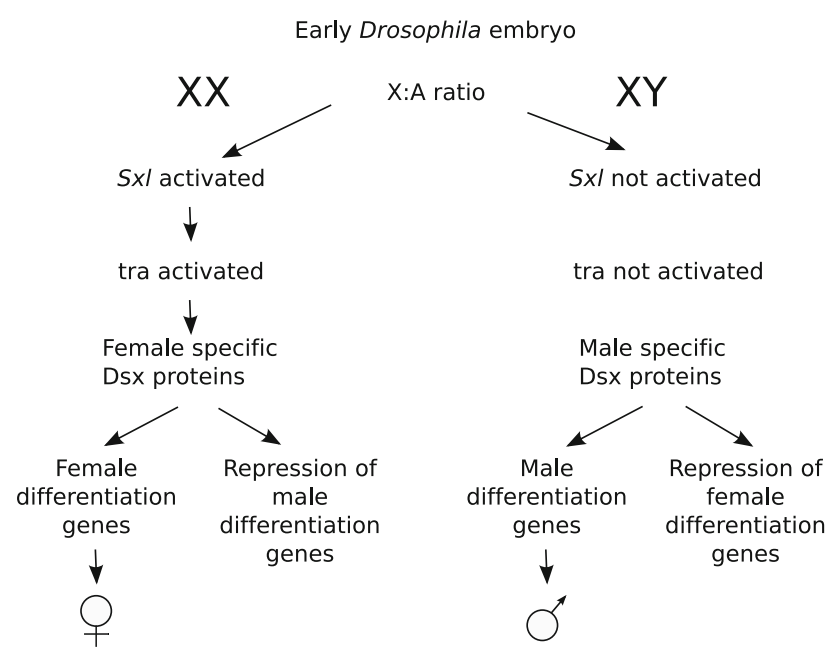

Fig. 3 The genetic sex determination cascade in Drosophila. Sexual development in Drosophila is determined by the ratio of X-chromosomes to autosomes which decides whether the $S x l$-gene is turned on, leading to the female pathway, or turned off, leading to male sexual development. Redrawn and simplified from Pomiankowski et al. (2004) and Gilbert (2000)
However, the mammalian sex determination system has proved to be more complex than the one-gene system proposed after the discovery of the $S R Y$-gene that determines testis formation (Berta et al. 1990; De Loof 2006). Antagonistic genes regulate gonad differentiation in mice: the loss of one gene produce sex reversal in males, the loss of another gene results in partial testes in females (Kim et al. 2006). This antagonistic balance between gene products for sex differentiation suggests that any genetic or environmental switch may tip the balance between the male and the female developmental pathways (see Fig. 3).

Interestingly, we now know that gene regulation in temperature-dependent as compared to genotypic sex determination is not as different as one might think. Recently, one of the genes that render sex-determining mechanisms thermosensitive has been identified in turtles (Valenzuela et al. 2006). In genetic sex determination, expression of genes on the sex chromosomes determines the inner environment that produces sex differentiation. In temperature-dependent sex determination, temperature at a special developmental period induces the expression of certain genes which in turn produce an inner environment that trigger sex differentiation (Valenzuela et al. 2006).

In species with plastic sex determination individuals of different sex cannot be separated on the basis of their genomes. For example, in two species of sequential hermaphrodite fish, both changing from females to males, (Serranidae and Labridae) there are no chromosome differences between females, males and hermaphrodites (Ruiz-Carus 2002).

To sum up this section, even though the existence of sexes and the cell differentiation often is conserved, sex determination mechanisms are very diverse, and transitions between genetic and environmental determination have occurred numerous times during evolution. The selective forces behind this pattern are not well understood. However, adaptive changes in sex determination system in response to ecological factors or sexually antagonistic selection are likely to be important explanations.

In any case, this diversity and evolutionary flexibility illustrates how sex itself cannot be viewed as a rigid phenotypic trait determined straight-forwardly by the genotype. Even when sex determination is "genetic", it is not just a matter of having a particular sex chromosome or not. As we now turn to traits differing between the sexes, the role of plasticity is even more apparent.

\section{Plasticity of Sexual Characters}

Among species, the appearance of females and males range from similar to very dimorphic and in many bird species, for example, the plumage shifts between seasons and is 
more sexually dimorphic during the breeding season. (Although our perception may mistakenly judge plumages as similar when they are actually dimorphic to conspecifics because of ultraviolet light reflections, there is undoubtedly a range between sexually monomorphic and dimorphic appearances.)

In many hummingbird species, plumage colouration is not strictly dimorphic in terms of male and female, but rather an individual may have female-like or male-like colouration regardless of its sex. In this case, rather than being an effect of mate choice or competition for mates, the plumage seems to be an effect of ecological factors and a sign by which dominance hierarchies are determined at food sites (Bleiweiss 2001). Similarly, female damselflies often occur in several morphs of which some have malelike colouration (Van Gossum et al. 1999).

Sexual characters are often very plastic even when the sex determination is genetic, for the reasons outlined above. Therefore it is possible or probable that most characters overlap extensively between the sexes, except for primary sex characters. The exception to this general pattern would be when the sexes occupy very different ecological niches, and of course strongly sexually selected characters as for example colour dimorphism in some bird species, size dimorphism in some pinnipeds or the antlers in some deer. Sexual selection theory has been successful in explaining such traits, for which it was formulated in the first place. It is worth noting, however, that it may be misleading to extrapolate too readily from such species with striking sexual dimorphism, and always expect similar differences elsewhere for the same reasons. Most species (humans, for instance) are no peacocks, elephant seals or elks, but show much more modest morphological differences-indicating weaker sexual selection or stronger genetic constraints. In fact, even close relatives of these showcase species for sexual selection often lack the dimorphism in question.

Moreover, many species have alternative reproductive phenotypes within the sexes, such as parental, satellite and sneaker males in blue-gill sunfish, among salmonid fishes there are small and big morphs of both males and females. In Coho salmon, the lifetime fitness of small sneaker/ co-operator males (Watters 2005) equals that of the large hook/coercer males (Gross 1985). Thus, disruptive selection may result in variation within sexes.

\section{Behaviour as a Reaction Norm}

Moving on to the behavioural attributes that differ between the sexes, sex differences in behaviour-can also be viewed as a reaction norm. Obviously, behaviour is plastic in all organisms, changing in response to environmental, social and internal circumstances, including an individual's sex. We do not in any way wish to dispute that sexual selection theory has provided very important tools for studying and understanding sex-roles.

Nevertheless, what we call "conventional" sex-roles in animals is based on traditional sexual selection theory (see e.g. Andersson 1994) and thus defined as males competing for female mating partners, using displays, aggression or other tactics (Vincent et al. 1992). This view-of undiscriminating, eager males and selective, coy femalesstems from Darwin (1871). Since sexual selection theory focus on reproductive success (matings leading to offspring), heterosexual behaviours are the centre of attention in evolutionary biology. We will not go further into variation of sexual behaviours here, but only note that there is abundant evidence of both same-sex and non-procreative sexual behaviours among animals (Bagemihl 1999).

Importantly for the present review, the sexes are not invariably associated with their respective roles as expected from sexual selection theory, even in taxa where the sex is irreversibly determined before sexual maturation. Figure 4 illustrates that sex-roles have been reversed numerous times during the course of evolution, in many taxa, such as insects, shorebirds and fishes. Furthermore, "reversed" sex-roles are viewed differently in different taxa: since, for example, male care is common in fish, exclusive paternal care in itself would not render a species to be defined as sex-role reversed, which could be the case in for example birds. What we call sex-roles in animals is thus not a dichotomy, but a continuum of behaviours connected to competition and mate choice.

Sex-roles have also been shown to be dynamic in several species (Kvarnemo and Ahnesjö 1996, 2002), for example two-spotted gobies Gobiusculus flavescens, in which males compete for females early during the season and late in the season females instead compete for males (Forsgren et al. 2004). In this species the change in sex-roles over the breeding season is correlated to a change in adult sex ratio. The abundance of males declined over the season, skewing the sex ratio towards females and leading to both reversed courtship and agonistic behaviour (Forsgren et al. 2004).

Hence, the continuum of characters associated with sex-from sex determination, the development of genitalia and sexual characters to sexually differentiated behaviour are all more or less flexible due to environmental effects. Sex, like any other trait, may be selected upon and change over evolutionary time.

\section{Prospects}

We have illustrated the large diversity in sex change, sex determination systems, and sex-roles found in nature and 


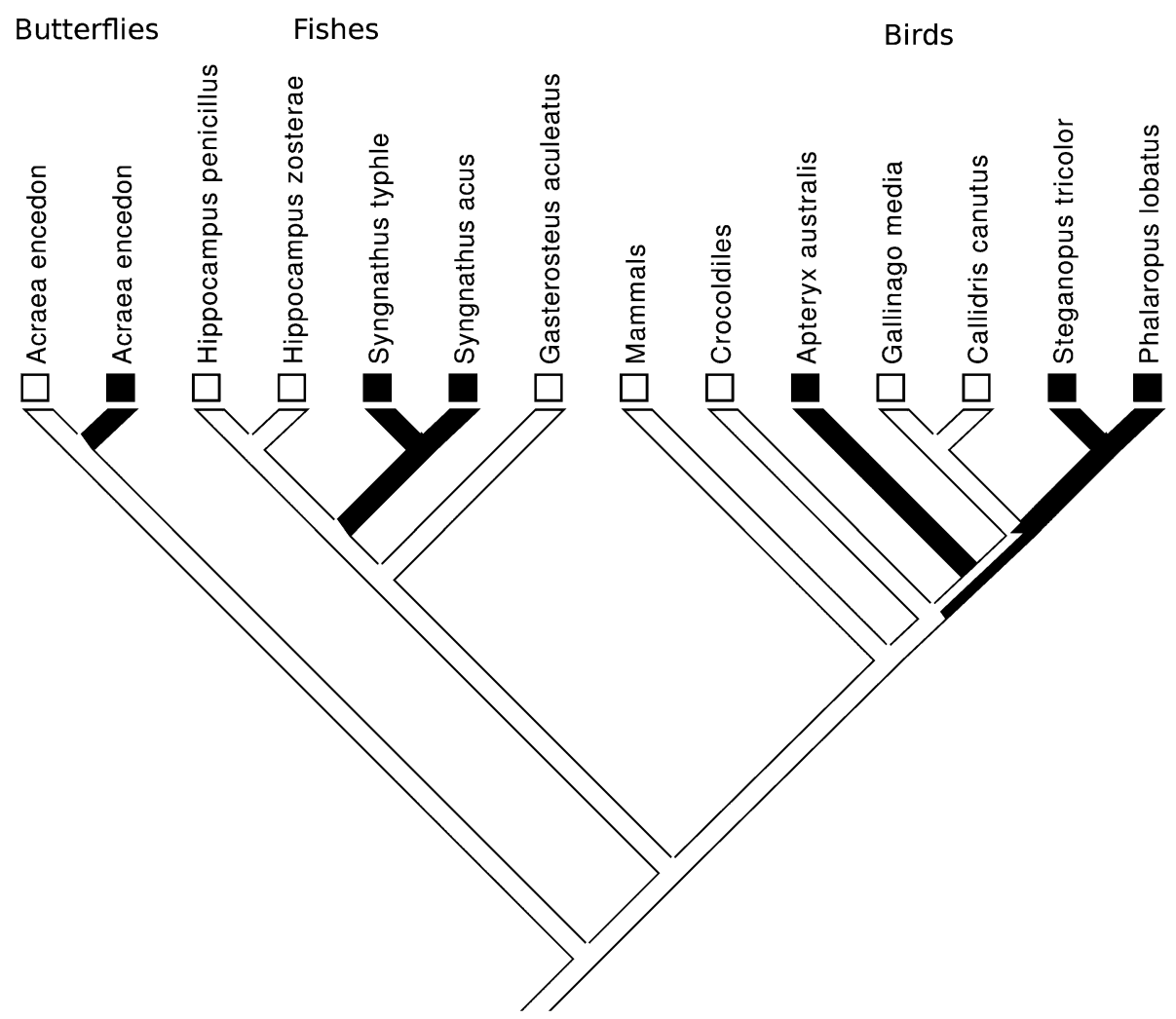

Fig. 4 Phylogeny of sex role-reversals. This phylogeny illustrates the variation in sex roles over evolutionary time. It is not representative for the whole tree of animal life as we have included only some examples of species with sex role reversal. Female butterflies (Acraea encedon) show sex role reversed swarming behaviour in Wolbachiainfected populations (Jiggins et al. 2000). Two groups are known for multiple origins of sex-role reversals, namely the pipefishes and their relatives and shorebirds. There are also a number of species that show flexible sex roles, such as two-spotted gobies and katydid insects. Black lineages indicate reversed sex roles, white lineages "conventional" sex roles and hatched branches show equivocal ancestral states. Phylogeny and sex role reversals in pipefishes are referred from Wilson et al. (2003). For shorebirds we used the phylogeny from Liker et al. (2001) and references on sex-role reversal from Zuk (2002) and Owens (2002)

guiding experimental design and by publication bias within research programmes. For this reason competing perspectives are valuable for scientific progress. We suggest that maybe we should pay more than lip service to the nullhypothesis and a priori expect no differences between the sexes, in order to better account for the diversity present in nature. It is important to note that the perspective we suggest here is not in opposition to sexual selection theory or to the basic Darwinian paradigm. Although Joan Roughgarden (2004) presents a similar view on the diversity of sex in nature, we do not claim that sexual selection is falsified as she does.

However, for a long time narrow-sense sexual selection theory has focused on sexual selection acting on males to understand the evolution of male ornaments and female preferences for these traits, i.e. genes for male indiscrimination and female choosiness (Gowaty and Hubbell 2005). Traditional sexual selection theory has emphasized female and male behaviours as an effect of anisogamy (Parker et al. 1972) and Parental investment (Trivers 1972). Thus, 
the classic text-book version of sexual selection is that in most species females have evolved to be choosy and males have evolved to be competitive and indiscriminate. Despite Darwin's original definition of sexual selection as differential reproductive success within a sex most studies have focused on variance in male reproductive success (as an effect of male-male competition and/or female choice).

Since the 1970s, female perspectives (e.g. Hrdy 1981), stochastic effects (Sutherland 1985, Hubbell and Johnson 1987, Gowaty and Hubbell 2005, 2009) and variable sex roles (e.g. Operational Sex Ratios) have been included in sexual selection theory and research. However, still the narrow-sense sexual selection view colour much theoretical and empirical practices. At the same time many empirical studies have examined alternative reproductive strategies, sex role reversals and condition-dependent sex change. As mentioned above, some authors have even used the reaction norm concept when describing for example sex change in fishes. Yet, we would like this variability to be acknowledged in the general picture of biological sexes, not merely as curious alternatives. We would like to change the frame of mind that researchers bring to issues involving sex, sex differences and behaviour. The reactionnorm-perspective on sex brings a more varied view on sex than does traditional sexual selection theory; however, new alternative sexual selection models are perfectly compatible with our view, for example Gowaty and Hubbell's models $(2005,2009)$. These models of flexible mate choice behaviour use gender-neutral assumptions to predict that both females and males flexibly adjust their mate choice decisions in relation to, for example, survival probabilities and encounter rates. It will be interesting to see whether these models better predicts mate choice patterns than traditional sexual selection theory.

Viewing sex explicitly as a reaction norm could be beneficial to scientific research itself, as it could lessen our biases in the research process. Since currently accepted theory risks limiting our ability to perceive the range of natural diversity, providing a gender-neutral model of sex will hopefully release constraints on our conception of what "male" and "female" characters and behaviour might imply. If biologists, from molecular scientists to animal behaviourists, when suggesting new hypotheses and performing experiments keep in mind that sex is a product of genetic and environmental influences on phenotypes resulting in tremendous variation in sex, sex attributes and behaviour, we will open our eyes to exploring the whole range of nature's diversity. Recognizing the flexibility in sex at a proximate as well as an ultimate level, enables us to explore predictions about adaptive changes in sex determination modes, morphology and behaviour. Mary Jane West-Eberhard has demonstrated that phenotypic plasticity give rise to alternative phenotypes and novel traits that can lead to divergence and speciation (WestEberhard 2003). West-Eberhard includes in her list of such alternative phenotypes workers and "queens" of social insects, different morphs of mimics in butterflies, as well as males and females in sexually reproducing species. Investigating sex as a reaction norm includes examination of selection and constraints on sex determination, sexual phenotypes and behaviours in different environments. Thus, viewing sex as a reaction norm can generate new testable hypotheses about processes generating diversity in nature.

It would also be beneficial to the society outside of academia to reveal the true variability in biological sex and sex differences. Sex is a particularly illustrative example of how the ubiquitous developmental plasticity of living systems means that biological determinism does not typically follow from biological theory. Evolutionary biology is not served by the caricatures of its results that are often shown in popular media, where new-found genes "for" this or the other trait are reported almost daily. One gene does not make a trait. This is important because evolutionary claims have effects on interpretations of not only animal behaviour but also human behaviour, political debates, policy making and legislation.

Acknowledgments Thanks to I. Ahnesjö, J. Bromseth, J. P. Drury, K. Eriksson, P. Gowaty, H. Götschel, T. Holmberg, an anonymous reviewer and many other colleagues that have given valuable input to the ideas presented in this manuscript. MA was supported by the GenNa-program at the Centre for Gender Research, Uppsala University during this work, by a grant from the Royal Swedish Academy of Sciences and the Swedish Research Council and SN by grants from the Swedish Research Council.

Open Access This article is distributed under the terms of the Creative Commons Attribution Noncommercial License which permits any noncommercial use, distribution, and reproduction in any medium, provided the original author(s) and source are credited.

\section{References}

Andersson, M. (1994). Sexual selection. Princeton: Princeton University Press.

Bagemihl, B. (1999). Biological exuberance: Animal homosexuality and natural diversity. London: Profile Books.

Berta, P., Hawkins, J. R., Sinclair, A. H., Taylor, A., Griffiths, B. L., Goodfellow, P. N., et al. (1990). Genetic evidence equating SRY and the testis determining factor. Nature, 348, 448-450.

Bleiweiss, R. (2001). Asymmetrical expression of transsexual phenotypes in hummingbirds. Proceedings of Royal Society of London B, 268, 639-646.

Bull, J. J. (1980). Sex determination in reptiles. The Quarterly Review of Biology, 55, 4-21.

Buss, L. W. (1987). The evolution of individuality. Princeton: Princeton University Press.

Darwin, C. (1871). The descent of man and selection in relation to sex. New York: Appleton. 
De Loof, A. (2006). Ecdysteroids: The overlooked sex steroids of insects? Males: The black box. Insect Science, 13, 325-338.

de Queiroz, K., Martins, E. P. (1996a). Squamata. Lizards and snakes. Version 01 January 1996 (temporary). http://tolweb.org/ Squamata/14933/1996.01.01 in The Tree of Life Web Project, http://tolweb.org/.

de Queiroz, K., Martins, E. P. (1996b). Iguania. Version 01 January 1996 (temporary). http://tolweb.org/Iguania/17559/1996.01.01 in The Tree of Life Web Project, http://tolweb.org/.

Ellegren, H. (2000). Evolution of the avian sex chromosomes and their role in sex determination. Trends in Ecology \& Evolution, 15(5), 188-192.

Fausto-Sterling, A. (1993). The five sexes: Why male and female are not enough. The Sciences May/April, 1993, 20-24.

Fausto-Sterling, A. (2000a). The five sexes revisited. The Sciences July/Aug, 2000, 18.

Fausto-Sterling, A. (2000b). Sexing the body, gender politics and the construction of sexuality. New York: Basic Books.

Fausto-Sterling, A., Gowaty, P. A., \& Zuk, M. (1997). Evolutionary psychology and darwinian feminism. Feminist Studies, 23(2), 403-417.

Fishelson, L. (1998). Behaviour, socio-ecology and sexuality in damselfishes (Pomacentridae). The Italian Journal of Zoology 65(Suppl. S), 387-398 .

Forsgren, E., Amundsen, T., Borg, Å. A., \& Bjelvenmark, J. (2004). Unusually dynamic sex roles in a fish. Nature, 429, 551-554.

Freeman, D. C., Harper, K. T., \& Charnov, E. L. (1980). Sex change in plants: Old and new observations and new hypotheses. Oecologia, 47, 222-232.

Froschauer, A., Braasch, I., \& Volff, J. N. (2006). Fish genomes, comparative genomics and vertebrate evolution. Current Genomics, 7, 43-57.

Gilbert, S. F. (2000). Developmental biology (6th ed.). Sunderland, MA: Sinauer Associates.

Gotthard, K., \& Nylin, S. (1995). Adaptive plasticity and plasticity as an adaptation: A selective review of plasticity in animal morphology and life history. Oikos, 74, 3-17.

Gowaty, P. A. (1997). Sexual dialectics, sexual selection and variation in reproductice behavior. In P. A. Gowaty (Ed.), Feminism and evolutionary biology, boundaries, intersections and frontiers (pp. 351-384). New York: Chapman and Hall.

Gowaty, P. A. (2003). Sexual natures: How feminism changed evolutionary biology. Signs, 28(3), 901-921.

Gowaty, P. A., \& Hubbell, S. P. (2005). Chance, time allocation, and the evolution of adaptively flexible sex role behavior. Integrative and Comparative Biology, 45, 931-944.

Gowaty, P. A., \& Hubbell, S. P. (2009). Reproductive decisions under ecological constraints: It's about time. PNAS, 106(Suppl. 1), 10017-10024.

Graves, J. A. M., Pleichel, C. L. (2010). Homologies in vertebrate sex determination-shared ancestry or limited options? Genome Biology 11, 205.

Gross, M. R. (1985). Disruptive selection for alternative life histories in salmon. Nature, 313, 47-48.

Hattori, A. (2000). Social and mating systems of the protandrous anemonefish Amphiprion perideraion under the influence of a larger congener. Austral Ecology, 25(2), 187-192.

Hillis, D. M., \& Green, D. M. (1990). Evolutionary changes of heterogametic sex in the phylogenetic history of amphibians. Journal of Evolutionary Biology, 3, 49-64.

Hrdy, S. B. (1981). The woman that never evolved. Cambridge: Harvard University Press.

Hrdy, S. B. (1986). Empathy, polyandry and the myth of the coy female. In R. Bleier (Ed.), Feminist approaches to science (pp. 119-146). New York: Pergamon Press.
Hubbell, S. P. \& Johnson, L. K. (1987). Environmental variance in lifetime mating success, mate choice, and sexual selection. American Naturalist 91-112.

Jiggins, F. M., Hurst, G. D. D., \& Majerus, M. E. N. (2000). Sexratio-distorting Wolbachia causes sex-role reversal in its butterfly host. Proceedings of the Royal Society of London Series B, 267, 69-73.

Kim, Y., Kobayashi, A., Sekido, R., DiNapoli, L., Brennan, J., Chaboissier, M.-C., et al. (2006). Fgf9 and Wnt4 act as antagonistic signals to regulate mammalian sex determination. PLoS Biology, 4(6), e187.

Kimchi, T., Jennings, X., \& Dulac, C. (2007). A functional circuit underlying male sexual behaviour in the female mouse brain. Nature, 448, 1009-1014.

Kraak, S. B. M., \& DeLooze, E. M. A. (1993). A new hypothesis on the evolution of sex determination in vertebrates-big females ZW, big males XY. Netherlands Journal of Zoology, 43, $260-273$.

Kvarnemo, C., \& Ahnesjö, I. (1996). The dynamics of operational sex ratios and competition for mates. Trends in Ecology \& Evolution, 11, 404-408.

Kvarnemo, C., \& Ahnesjö, I. (2002). Operational sex ratios and mating competition. In I. C. W. Hardy (Ed.), Sex ratios: concepts and research methods (pp. 366-382). Cambridge: Cambridge University Press.

Laland, K. N., \& Janik, V. M. (2006). The animal cultures debate. Trends in Ecology \& Evolution, 21, 542-547.

Lande, R. (1987). Genetic correlations between the sexes in the evolution of sexual dimorphism and mating preferences. In J. W. Bradbury \& M. B. Andersson (Eds.), Sexual selection: Testing the alternatives (pp. 83-94). Chichester: Wiley.

Lawton, M. F., Garstka, W. R., \& Hanks, J. C. (1997). The mask of theory and the face of nature. In P. A. Gowaty (Ed.), Feminism and evolutionary biology, boundaries, intersections and frontiers (pp. 63-85). New York: Chapman \& Hall.

Leimar, O., Hammerstein, P., \& Van Dooren, T. J. M. (2006). A new perspective on developmental plasticity and the principles of adaptive morph determination. American Naturalist, 167, 367-376.

Liker, A., Reynolds, J. D., \& Székely, T. (2001). The evolution of egg size in socially polyandrous shorebirds. Oikos, 95, 3-14.

Maddison, D. R., Schulz, K.-S., (Eds.) (1996-2006). The tree of life web project. http://tolweb.org.

Mank, J. E., Promislow, D. E., \& Avise, J. C. (2006). Evolution of alternative sex-determining mechanisms in teleost fishes. Biological Journal of the Linnean Society, 87, 83-93.

Matsubara, K., Tarui, H., Toriba, M., Yamada, K., Nishida-Umehara, C., Agata, K., et al. (2006). Evidence for different origin of sex chromosomes in snakes, birds, and mammals and step-wise differentiation of snake sex chromosomes. Proceedings of the National Academy of Science, 103, 18190-18195.

Munday, P. L., Buston, P. M., \& Warner, R. R. (2006a). Diversity and flexibility of sex-change strategies in animals. Trends in Ecology \& Evolution, 21, 89-95.

Munday, P. L., White, J. W., \& Warner, R. R. (2006b). A social basis for the development of primary males in a sex-changing fish. Proceedings of the Royal Society of London Series B, 273(1603), 2845-2851.

Nakagawa, S. (2004). Is avian sex determination unique? Clues from a warbler and from chickens. Trends in Genetics, 20, 479-480.

Owens, I. P. F. (2002). Male-only care and classical polyandry in birds: Phylogeny, ecology and sex differences in remating opportunities. Philosophical Transactions of the Royal Society of London Series B, 357, 283-393. 
Parisi, M., Nuttall, R., Edwards, P., Minor, J., Naiman, D., Lü, J., et al. (2004). A survey of ovary-, testis- and soma biased gene expression in Drosophila melanogaster adults. Genome Biology, 5, R40.

Parker, G. A., Baker, R. R., \& Smith, V. G. F. (1972). The origin and evolution of gamete dimorphism and the male-female phenomenon. Journal of Theoretical Biology, 36, 529-553.

Pieau, C., Dorizzi, M., \& Richard-Mercier, N. (1999). Temperaturedependent sex determination and gonadal differentiation in reptiles. Cellular and Molecular Life Sciences, 55, 887-900.

Policansky, D. (1982). Sex change in plants and animals. Annual Review of Ecology and Systematics, 13, 471-495.

Pomiankowski, A., Nöthiger, R., \& Wilkins, A. (2004). The evolution of the Drosophila sex-determination pathway. Genetics, 166, 1761-1773.

Richerson, P. J., \& Boyd, R. (2005). Not by genes alone: How culture transformed human evolution. Chicago: University of Chicago Press.

Roughgarden, J. (2004). Evolutions rainbow, diversity, gender and sexuality in nature and people. Berkeley: University of California Press.

Rubenstein, D. R., \& Hauber, M. E. (2008). Dynamic feedback between phenotype and physiology in sexually selected traits. Trends in Ecology \& Evolution, 23(12), 655-658.

Ruiz-Carus, R. (2002). Chromosome analysis of the sexual phases of the protogynous hermaphrodites Epinephelus guttatus and Thalassoma bifasciatum (Serranidae and Labridae; Teleostei). Carribean Journal of Science, 38(1-2), 44-51.

Schlichting, C. D., \& Pigliucci, M. (1998). Phenotypic evolution, a reaction norm perspective. Sutherland, MA: Sinauer Associates.

Shine, R. (1999). Why is sex determined by nest temperature in many reptiles? Evolutionary Ecology, 14, 186-189.

Shine, R., Elphick, M. J., \& Donnellan, S. (2002). Co-occurrence of multiple, supposedly incompatible modes of sex determination in a lizard population. Ecological Letters, 5, 486-489.

Stearns, S. C., \& Hoekstra, R. F. (2005). Evolution: An introduction. Oxford: Oxford University Press.

Sutherland, W. J. (1985). Chance can produce a sex difference in variance in mating success and account for Bateman's data. Behaviour, 1349-1352.
Trivers, R. L. (1972). Parental investment and sexual selection. In B. Campbell (Ed.), Sexual selection and the descent of man (pp. 136-179). Chicago: Aldine.

Valenzuela, N., LeClere, A., \& Shikano, T. (2006). Comparative gene expression of steriodogenic factor 1 in Chrysemys picta and Apalone mutica turtles with temperature-dependent and genotypic sex determination. Evolution and Development, 8(5), 424-432.

Van Doorn, G. S., \& Kirkpatrick, M. (2007). Turnover of sex chromosomes induced by sexual conflict. Nature, 449, 909-912.

Van Gossum, H., Stoks, R., Matthysen, E., Valck, F., \& De Bruyn, L. (1999). Male choice for female colour morphs in Ischnura elegans (Odonata, Coenagrionidae): Testing the hypotheses. Animal Behaviour, 57(6), 1229-1232.

Via, S., \& Lande, R. (1985). Genotype-environment interaction and the evolution of phenotypic plasticity. Evolution, 39, 505-522.

Vincent, A., Ahnesjö, I., Berglund, A., \& Rosenqvist, G. (1992). Pipefishes and seahorses: are they all sex role reversed? Trends in Ecology \& Evolution, 7, 237-241.

Warner, R. R., \& Lejeune, P. (1985). Sex change limited by paternal care: A test using four Mediterranean labrid fishes, genus Symphodus. Marine Biology, 87, 89-99.

Watters, J. V. (2005). Can the alternative male tactics 'fighter' and 'sneaker' be considered 'coercer' and 'cooperator' in coho salmon? Animal Behaviour, 70, 1055-1062.

West-Eberhard, M. J. (2003). Developmental plasticity and evolution. New York: Oxford University Press.

Wilkinson, T. (1998). Wolbachia come of age. Trends in Ecology \& Evolution, 13(6), 213-214.

Wilson, A. B., Ahnesjö, I., Vincent, A. C. J., \& Meyer, A. (2003). The dynamics of male brooding, mating patterns, and sex roles in pipefishes and seahorses (family Syngnathidae). Evolution, 57(6), 1374-1386.

Yang, X., Schadt, E. E., Wang, S., Wang, H., Arnold, A. P., IngramDrake, L., et al. (2006). Tissue-specific expression and regulation of sexually dimorphic genes in mice. Genome Research, 16, 995-1004.

Zuk, M. (2002). Sexual selections, what we can and can't learn about sex from animals. Berkeley: University of California Press. 